\title{
EXTRA CORPOREAL SHOCK WAVE LITHOTRIPSY AND INTRACORPOREAL LASER LITHOTRIPSY FOR DISTAL URETERIC CALCULI - A COMPARATIVE STUDY ON EFFICACY AND SAFETY
}

\author{
RAHMAN MM ${ }^{1}$, CHOWDHURY MSA $^{1}$, RAHMAN MM $^{1}$, ISLAM N$^{2}$, SAHA PK $^{1}$, ISLAM MN $^{3}$, \\ HOSSAIN AZMZ ${ }^{4}$
}

\begin{abstract}
:
Purpose: We compared the efficacy, safety and treatment outcome after ESWL and URS \& Laser lithotripsy for distal ureteric stones.

Materials and Methods: We evaluated 60 consecutive patients who underwent ESWL $(n=30)$ and URS \& Laser lithotripsy $(n=30)$ for a single radio-opaque distal ureteric stone. Stone fragmentation and clearance was checked by fluoroscopy at the end of procedure. Stone free rates defined as no visible fragment on a plain x-ray, complication and patients' satisfaction were compared.

Result: Immediate stone clearance, complication rate, operation time and hospital stay were compared between two groups. Immediate stone clearance was significantly higher in group- $B$ $(86.66 \%)$ than that in group-A (66.66\%) $p<0.05$. The complication rate were lower in group $B$ $(33.30 \%)$ than that of group-A (50\%) but the difference did not turn to significant $p>0.05$. The mean operation time was significantly less in group- $A$ than that in group- $B(31.17 \pm 3.87$ vs $49.83 \pm 4.99$ minutes, $p<0.001)$. However no significant difference was observed between the

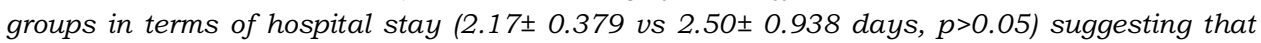
ureteroscopic laser lithotripsy is better option than extracorporeal shockwave lithotripsy for clearance of distal ureteric stone.
\end{abstract}

Conclusion: URS \& Laser lithotripsy is better option for the management of distal ureteric stone in term of better immediate stone clearance and less complication.

Key words: ESWL, URS, Laser lithotripsy, distal ureteric stone.

J Dhaka Med Coll. 2012; 21(1) : 8-11.

\section{Introduction:}

Urinary Stone disease is a systemic, metabolic, recurrent and lifelong disease. The prevalence of the urinary tract stone disease is estimated $2 \%-3 \%{ }^{1}$. Male to Female ratio is $3: 1^{2}$ the peak incidence of urinary calculi is from twenties to forties ${ }^{3}$. Treatment of ureteric stone depends on stone size, composition, position and degree of obstruction, pain, presence of infection, single kidney, abnormal ureteral anatomy. Ureteric calculi are associated with pain and or renal obstruction; care must be taken to prevent irreversible damage to the kidney, whether choosing expectant or active treatment. The goal of surgical management of ureteric calculi is to achieve complete stone clearance with minimal morbidity to the patient.Treatment of stone disease moved dramatically from an open operative procedure to endoscopic, minimally invasive and noninvasive procedure, mainly extracorporeal shock wave lithotripsy (ESWL) and ureteroscopy with lithotripsy. ESWL and URS with lithotripsy are both treatment modalities that have been established for the treatment of ureteric calculi. For both modalities stone free rates of more than $90 \%$ have been reported ${ }^{4}$. ESWL and

1. Dr. Md. Mostafizur Rahman, Dr. Md. Shafiqul Alam Chowdhury, Dr. Md. Mizanur Rahman, Dr. Prodyut Kumar Saha, Assistant Professor, Department of Urology, DMCH, Dhaka

2. Dr. Nazrul Islam, Assistant Professor, Department of Nephrology, DMCH, Dhaka

3. Dr. Md. Nazmul Islam, Assistant Registrar, Department of Urology, DMCH, Dhaka

4. Prof. AZM Zahid Hossain, Professor of Urology.

Correspondence : Dr. Md. Mostafizur Rahman, Assistant Professor, Department of Urology, DMCH, Dhaka 
URS are regarded as effective modalities with low complication rate for distal ureteric stone. Due to advancement in lithotripsy design and fluoroscopic imaging has currently allowed successful identification and in situ treatment of calculi in distal ureter. With ESWL ureteric calculi are fragmented into smaller fragments by shock waves and can then pass spontaneously as small fragments. ESWL is non invasive, requires fewer anaesthesia than other treatment for ureteric stones, and may render patients stone free without surgical intervention or endoscopic procedures. In situ extra corporeal shock wave lithotripsy for treatment of distal ureteric stone has a stone free rate of $76 \% \%^{5}$. Ureteroscopy is a common procedure in Bangladesh and most of the urologist use pneumatic lithotripsy for distal ureteric stone. Laser lithotripsy is a new procedure in our country and is used for urinary calculi fragmentation. Holmium: YAG laser is commonly used in different field of urology. With the introduction of this type of laser ureteric stone irrespective of location can be managed by semi rigid ureterorenoscopy. It has been shown that Holmim:YAG lithotripsy is better among other energy source in terms of efficacy and safety. Many comparative studies between ESWL and Laser lithotripsy for the management of distal ureteric stone has been under taken in different parts of the world, no such study has yet been done in Bangladesh. This present study has been designed to compare the outcome of ESWL and Laser lithotripsy for fragmentation of distal ureteric stone.

\section{Methods:}

The study was a prospective comparative study, conducted in the Department of Urology, Dhaka Medical college Hospital from January 2005 to December 2006. Study population included the patients who attended in out patients department of urology, Dhaka Medical College Hospital, Dhaka with distal ureteric stone. A total 60 patients were evaluated by their history, physical findings and investigation (Urinalysis, USG of KUB, S. creatinine and IVU) and were primarily selected for admission.

Inclusion criteria were patient between age ranges 18 to 70 years and patients with distal single ureteric stone. Stone present in proximal part of ureter, multiple ureteric calculi, stone with infection, bleeding disorder, pregnancy and patient previously treated by ureterolithotomy were excluded.

After admission patients were again studied clinically and 60 patients, ages ranging from 18 to 70 years were selected for this study as per selection criteria.

All the cases were numbered chronologically, and odd numbers grouped as group $A$ and was treated by ESWL, even number as Group B and were treated by URS and Intra corporeal laser lithotripsy. Patients of group A were treated by in situ ESWL by Siemens Lithostar machine, where electromagnetic shock wave energy is used to fragment the stone. Procedure done under sedation with injection diazepam $10 \mathrm{mg}$ $\mathrm{I} / \mathrm{M}$ and diclofenac sodium $50 \mathrm{mg} \mathrm{I} / \mathrm{M}$ was given as analgesic. Patient was in prone position; stone was visualized with fluoroscopy and centered to the shock wave generator. Coupling was done later on and the level of shock energy was progressively stepped up till satisfactory stone fragmentation within patient's comfort. Maximum 3000 wave can be generated for single session. Completion of fragmentation was visualized by fluoroscopy.

Patients of group B were treated by URS and Intra corporeal laser lithotripsy. The procedure was done under spinal anaesthesia . Cystoscopy was done for identification of ureteric orifice and guide wire was passed within ureteric orifice under visual and fluoroscopic monitoring. As soon as stone was seen the laser fiber was pushed to stone, it was fixed to the stone, laser source was on and stone fragmentation started, care has to taken to avoid injury of ureter and keeping eye on stone fragment migration, placement of D-J stent at the end of procedure was left to the discretion of the operating surgeon. Ureteric injury is noted when abrasion of ureteral mucosa is identified and ureteral perforation is noted when any hole is identified within the ureter. Stone clearance was checked by ureteroscopy and fluoroscopy at the end of procedure.

Data was collected of variable of interest (stone size, operation time, stone clearance, 
haematuria, hospital stay) using a structured data collection sheet. Data were processed and analyzed using software SPSS. Test statistics used to analyze the data Chi-square test, student t-test (unpaired), Fisher's Exact probability test.

\section{Result:}

There was no significant difference in demographic and clinical variables between two groups in terms of age, sex, stone size, operation time $(p>0.05)$.

Table-I demonstrates the comparison of stone size that might have influence on the outcome of intervention. The variables chosen were stone size, IVU excretion delayed, IVU (P-C) system dilated. None of these variable was found to vary between groups as evident by p.0.05.

\section{Table-I}

\begin{tabular}{lccc}
\hline Clinical variables & $\begin{array}{c}\text { Group-A } \\
(\mathrm{n}=30)\end{array}$ & $\begin{array}{c}\text { Group-B } \\
(\mathrm{n}=30)\end{array}$ & $\begin{array}{c}\text { P- } \\
\text { Values }\end{array}$ \\
\hline $\begin{array}{l}\text { Stone size } \\
\text { (Mean } \pm \text { SD })\end{array}$ & $10.20 \pm 1.88$ & $10.63 \pm 2.31$ & 0.429 \\
$\begin{array}{l}\text { IVU, excretion } \\
\text { delayed,n(\%) }\end{array}$ & $8(26.7)$ & $10(33.3)$ & 0.573 \\
$\begin{array}{l}\text { IVU(P-C) system } \\
\text { diated, } \mathrm{n}(\%)\end{array}$ & $17(56.7)$ & $18(60.0)$ & 0.793 \\
\hline
\end{tabular}

Table-II : compare the outcome of the two groups. The outcome variables were immediate stone clearance, complication rate, operation time and hospital stays. Immediate stone clearance rate was significantly higher in group $-\mathrm{B}(86.66 \%)$ than that in group-A $(66.66 \%) ; \mathrm{p}<0.05$. The complication rate was lower in group-B (33.3\%) than that of group -A $(50 \%)$ but the difference did not turn to significant; $p>0.05$. The mean operation time was significantly less in group- A than that in group -B (31.17 \pm 3.87 vs $49.83 \pm 4.99$ minutes, $\mathrm{p}<0.001$ ). however, no significant difference was observed.Between the groups in terms of hospital stay $(2.17 \pm 0.379$ vs $2.50 \pm 0.938$ days, $\mathrm{p}>0.05$ ) suggesting that ureteroscopic laser lithotripsy is better option than extracorporeal shockwave lithotripsy for clearance of distal ureteric stone.
Table-II

\begin{tabular}{lccc}
\hline Clinical variables & $\begin{array}{c}\text { Group-A } \\
(\mathrm{n}=30)\end{array}$ & $\begin{array}{c}\text { Group-B } \\
(\mathrm{n}=30)\end{array}$ & $\begin{array}{c}\text { P- } \\
\text { Values }\end{array}$ \\
\hline $\begin{array}{l}\text { Immediate stone } \\
\text { clearance, n (\%) }\end{array}$ & $20(66.66)$ & $26(86.66)$ & 0.012 \\
$\begin{array}{l}\text { Complication rate, } \\
\text { n(\%) }\end{array}$ & $15(50.0)$ & $10(33.3)$ & 0.190 \\
$\begin{array}{l}\text { Mean operation } \\
\text { time(Minutes) }\end{array}$ & $31.17 \pm 3.87$ & $49.83 \pm 4.99$ & $<0.001$ \\
Mean hospital & $2.17 \pm 0.379$ & $2.50 \pm 0.938$ & 0.079 \\
stay(Days) & & & \\
\hline
\end{tabular}

\section{Discussion:}

The findings derived from data analysis leaves some scope for discussion to arrive at a conclusion. Ureteroscopic Holmium: YAG laser lithotripsy was used in 168 patients of ureteric calculi (mostly distal ureteric stone 108). The stone free rate was $94 \%(102 / 108)$ of distal ureteric stone. The complication rate was $5 \%$ (8 cases). They concluded Holmium: YAG laser lithotripsy is highly effective and safe treatment modalities (Pang LL et al. 2004) ${ }^{6}$.

47 ureteroscopic laser lithotripsy were performed in 44 patients, out of them 37 patients had stone in the lower ureter, the success rate was $91 \%$ (yiu MK, et al 1996) ${ }^{7}$. In a retrospective study they evaluated the efficacy of ureteroscopic lithotripsy and ESWL in the treatment of middle and lower ureteric stone from Jan 1996 to march 1997 by SKH Yip, et $\mathrm{al}^{8}$. Total 61 patients treated by URS using Holmium laser and 49 patients treated by ESWL. Single session stone clearance rate of $100 \%$ and $95 \%$ for middle and lower ureteric stone respectively. ESWL had a single session rate $67 \%$ and overall success rate of $87 \%$ after retreatment.

To determine the efficacy and cost of ESWL compared with URS in the treatment of mid and lower ureteric stone were analyzed retrospectively. Treatment with ESWL included 63 patients and URS in 105 patients. ESWL for mid and lower ureteric calculi resulted in a success rate of $90 \%$ and $81 \%$ respectively compared with $96 \%$ and $99 \%$ for URS. The cost of URS were higher than those of ESWL ${ }^{9}$. 
In a prospective non randomized study of total 124 patients with distal ureteric calculi done by P. Honeck, et al $2006^{10}$ among them 62 patients treated with ESWL and 62 patients with URS and laser lithotripsy.84\% have stone free occur rate within 7 days, 98\% after URS. This result shows a significant success $\mathrm{p}=0.005$ in favour of URS.

A prospective non randomized study was conducted to compere the success, efficacy and complication of URS and ESWL for the treatment of symptomatic small non obstructing lower ureteric calculi, a total 280 patients were included in this study of those 160 patients were treated by URS and 120 patients were treated by ESWL. URS achieved complete stone clearance in $98.7 \%$ of patients, of the 120 patients treated by ESWL 90\% achieved stone free status at 3 months ${ }^{11}$.

Ureteroscopic holmium: YAG laser lithotripsy was used in 168 patients of ureteral calculi (mostly distal ureteric stone 108). The stone free rate was $94 \%(102 / 108)$ of distal ureteric stone. The complication rate was $5 \%(8$ cases $)$. They concluded ureteroscopic holmium :YAG laser lithotripsy is a highly effective and safe treatment modalities ${ }^{12}$.

\section{Conclusion:}

URS \& Laser lithotripsy is better option for the management of distal ureteric stone in term of better immediate stone clearance and less complication.

\section{References}

1. Uribarri J, Oh MS, Carroll HJ. The first kidney stone. Ann Intern Med 1989; 111(12): 1006-9.

2. Watterson JD, Girvan AR, Cook AJ, Beiko DT, Nott L, Auge BK, et al. Safety and efficacy of holmium: Yag laser lithotripsy in patients with bleeding diatheses. J Urol 2000; 168(2): 442-5.
3. Pak CY. Medical management of nephrolithiasis in Dallas: update 1987. J Urol 1988; 140(3): 4617 .

4. Segura JW, Preminger GM, Assimos DG, Dretler SP, Kahn RI, Lingeman JE, et al. Ureteral Stones Clinical Guidelines Panel summary report on the management of ureteral calculi. J Urol 1997; 158(5): 1915-21.

5. Seong SJ, Ji- Hwan, Kyu SL. A comparison of holmium: YAG laser with Lithoclast lithotripsy in ureteral calculi fragmentation. Int J Urol 2005; 12(6): 544-7.

6. Pang ZL, Xiao CG, Zeng PQ, Lu GC, Zhang QJ. Ureteroscopic Holmium: YAG laser lithotripsy for managing urinary tract calculi. [Article in Chinese] [Abstract]. Zhonghua Wai Ke Za Zhi 2004; 42(2): 92-3.

7. Yiu MK, Liu PL, Yiu TF, Chan AYT. 1996, Clinical experience with holmium: YAG laser lithotripsy of ureteral calculi. Lasers Surg Med 1996; 19(1): 103-6.

8. Yip SKH, Lee FCW, Tam PC, Leung SYL. Outpatient treatment of middle and lower ureteric stones: extracorporeal shock wave lithotripsy versus ureteroscopic laser lithotripsy. Ann Acad Med Singapore 1998; 27(4): 515-9.

9. Bierkens AF, Hendrikx AJM, De La Rossette JJMCH, Stultiens GNM, Beerlage HP, Arends AJ, et al. Treatment of mid- and lower ureteric calculi: extracorporeal shock-wave lithotripsy vs laser ureteroscopy: a comparison of costs, morbidity and effectiveness. Br J Urol 1998; 81(1): 31-5.

10. Honeck P, Hacker A, Alken P, Michel MS, Knoll T. Shock wave lithotripsy versus ureteroscopy for distal ureteral calculi: a prospective study. Urol Res 2006; 34(3): 190-2.

11. Andankar MG, Maheshwari PN, Saple AL, Mehta V, Varshney A, Bansal B. Symptomatic small nonobstructing lower ureteric calculi: comparison of ureteroscopy and extra corporeal shock wave lithotripsy. J PostGrad Med 2001; 47(3): 177-80.

12. Ghafoor M, Halim A. Extracorporeal shockwave lithotripsy in the treatment of ureteric stone: experience from Tawam Hospital, United Arab Emirates. Ann Saudi Med 2002; 22(1-2): 18-21. 